\title{
Research on the Establishment of Chinese Rural Drinking Water Market
}

\section{Jian-Fei Leng, Yi-Ran Ding}

Finance Department, School of Business, Hohai University, Nanjing, China.

Email: ljf200209@gmail.com, graceding1002@126.com

Received September $4^{\text {th }}$, 2012; revised October $6^{\text {th }}$, 2012; accepted November $8^{\text {th }}, 2012$

\begin{abstract}
The aim of this paper is to research the establishment of Chinese rural drinking water market. On the basis of prior research on rural drinking water and water market, we study the market establishment and analyze trading elements, procedure and modes of Chinese rural drinking water market. Then we explore the operating mechanism of the market, such as the supply and demand mechanism, the price mechanism, the competition mechanism and the support mechanism. This study will conduce to the optimization of the allocation of water resources.
\end{abstract}

Keywords: Rural Drinking Water; Water Market; Operating Mechanism

\section{Introduction}

Currently, China's rural population is about 650 million, according to the major macroeconomic data in 2011, which is announced by China National Bureau of Statistics on January 17, 2012. There is a persist problem of Chinese rural drinking water because of such large rural population, coupled with constrains of the natural economic and social conditions, and the growing water pollution. The data of the second national agricultural census shows that $10.3 \%$ of the rural residents have difficulties in accessing to drinking water. The issue of rural drinking water is related to the vital interests of the survival, living and production of rural residents and is an important part of new countryside construction with Chinese characteristics. The government attaches great importance to rural drinking water. For instance, Central Document No. 1 in 2011 clearly points out that China should continue promoting the safety establishment of rural drinking water, solve the issues of rural drinking water safety in plan in 2013, and generally settle the problem of additional population with unsafe rural drinking water. In this context, it is both theoretically and practically significant to study the establishment of Chinese rural drinking water applying the theories and methods of capital market. The research will conduce to

"Funds: The special fund for public service sectors' research of ministry of water resources "the standards and evaluation of rural water conservancy construction for well-off society (201001037)" and the philosophy and social science fund for universities and colleges of Jiangsu province "research on the evaluation of sustainable development of China’s aquatic environment”. the expansion of the area and content of research on rural drinking water and the improvement of the theory system of rural drinking water security and rural drinking water market. It will also make for optimizing the allocation of rural drinking water through market regulation and promoting the development of water-saving society.

On the basis of prior research on rural drinking water and water market, we study the market establishment, analyzing trading elements, procedure and modes of Chinese rural drinking water market. Then we explore the operating mechanism of the market, such as the supply and demand mechanism, the price mechanism, the competition mechanism and the support mechanism. This study will help to optimize the allocation of water resources and establish Chinese rural drinking water market healthily and efficiently.

The paper is organized as follows: Section 1 is the introduction of the research. Section 2 discusses prior research on rural drinking water and water market. Section 3 describes the establishment of Chinese rural drinking market. Section 4 presents the operating mechanism of the market. Section 5 draws some conclusions.

\section{Prior Research on Rural Drinking Water and Water Market}

\subsection{Rural Drinking Water}

There is little research on rural drinking water in developed countries. For instance, in the US, drinking water is not a difficult problem in rural areas because the towns of rural America are equipped with water supply. And 
these living in their own land drill deep wells for water, the quality of which is inspected by the drilling companies and the service agencies. In Canada, there are drinking water problems in some rural areas. Parsons [1] investigated the problem of unsafe rural drinking water in Yellow Quill First Nations, eastern Saskatchewan, Canada. Peterson [2] pointed out that disease is closely contacted with unsafe drinking water in Canadian rural areas and unsafe drinking water affect the health of fetus and infant. Jones [3] studied the management of rural drinking water and emphasized the importance of communities in drinking water management.

Aiguo Jie [4] thought that the system is the foundation of management and that the property and responsibilities should be clearly defined, when researched rural drinking water problem. Chengxin Ma [5] stressed the significance of rural water supply project which is a solution of disaster and poverty in rural areas. Fenghua Gao [6] put forward different construction modes of safe rural drinking water projects and different water supply modes. Hansong Zhang [7] explored a managing mode of water users association of rural drinking water project based on the management model of irrigation water association. Yuanqing Yang and Qingjiang Pang [8] found the improvement of the safety problem of rural drinking water. They examined the quality of rural drinking water, the factors affecting water safety and the problems existing, and proposed some security measures and recommendations. Meng Hu et al. [9] discovered that the automatic control system is widely used in projects of safe rural drinking water and plays a good role in secure and efficient water supply. Jiaoyan Li [10] tested the operating management of rural drinking water projects in Zhangqiu, China, discovering the situation and problems of the project management and concluding some successful experience.

\subsection{Water Market}

Vaux et al. [11] applied a non-linear model to the research of agricultural water rights transferring to industrial and urban water rights in California, US, finding that water rights market can improve the allocation efficiency of water resources effectively and bring considerable economic benefits for market participants. Rosengrant [12] held the view that water market could encourage water users to improve the efficiency of water use and make water resources to flow from low efficiency to high efficiency. Mateen [13] explored many limiting factors of the establishment of water rights market, such as the definition of water rights, the improvement of the infrastructure of water metering and transferring, the problems of monopoly. Manuel [14] evaluated the influence of water rights market on agricultural income and employment rate in south Spain, thinking that farmers with small and medium scale are able to get greater benefits from water rights market. Howe et al. [15] analyzed the impact of institutional arrangements, economic environment and the form of water rights definition on water rights market through the comparison of three different water rights markets of Colorado River, California, US. Hadjigeorgalis [16] discussed various challenges faced by developed and developing countries in water markets and raised some recommendations.

He Huang [17] proposed to establish a trading system of water rights, separate from land ownership and develop conflict-resolving mechanism. Aihua Jiao et al. [18] researched the issue of Chinese water market establishment. Angang Hu [19] thought the water market should be supported by consultation system of political democracy and the interest compensation mechanism. Yuanyuan $\mathrm{Li}$ [20] analyzed the role and characteristics of water market and came out with some measures to develop water market. Yanxiang Ge et al. [21] studied the supply and demand mechanism, the price mechanism and the competition mechanism in water market operating. Xiaoqing Ma [22] brought up the basic framework of Chinese water rights market. Huajian Jiang and Honglin Pan [23] demonstrated the indispensable influence of administrative monopoly on water market operating.

\subsection{Comments on Prior Research}

We can summarize that research on rural drinking water is more concentrated in the construction and management of drinking water projects and protection measures of rural drinking water, and that research on water market primarily focused on water rights market. For the moment, few scholars combine rural drinking water and water market, and this paper study the establishment of rural drinking water market in China, which makes up for the deficiencies of the current study.

\section{The Establishment of Chinese Rural Drinking Water Market}

\subsection{Trading Elements}

\section{1) Subjects}

The trading subjects of rural drinking water consist of the buyers and the sellers. The buyers of rural drinking water can mainly be divided into three types, according to their different trading purposes. The first one is with real demand, whose trading purpose is to use it. This kind of demand subjects includes existing water users, as well as new entrants. For existing water users, their purchase behavior is due to the expansion of water consumption. And new entrants have to obtain necessary water resources through the market of rural drinking water. The second one is with the speculative demand, whose goal is to earn a premium, buying at a low price 
and selling at a high price. Moderate speculation can increase the activity of water market, however, supervision to the speculative demand need to be strengthen in that excessive speculation will seriously affect normal water-using and diminish social stability and development. The third one is for the purpose of stabilizing rural drinking water market and the main body of this demand is the government. In a falling market, the prices of rural drinking water is too low, so the government can directly intervene in the market, buying water, to guide prices to recover and protect the stability of rural drinking water market.

The sellers of rural drinking water are the holders of it and can also be divided into three types. The first one is with saving water which forms the main supply of rural drinking water market. Under certain price incentives, such providers will adjust their behavior of water consumption and increase water-saving input to maximize their interests through the transaction of rural drinking water. The second one is the speculators with profitdriven behavior. They will become the providers in the conditions of appropriate prices. The third one is also the government. When the market is overheated and the prices are too high, the government can sell rural drinking water in order to stabilize the prices and the market.

\section{2) Object}

The trading object of rural drinking water market is rural drinking water. Social water resources can be generally divided into three categories: water for basic use, water for ecological and environmental use and water for economic use. Water for basic use is domestic water, which is essential to human's survival and development. Water for ecological and environmental use is the necessary water resources to maintain a balanced ecological environment system. Water for economic use is the competitive water for industrial or agricultural use. Only water for economic use can be traded in the market because the transaction in water market must follow the principle that minimizing the impact on human's basic survival need and the sustainability of water resources.

Considerable part of rural drinking water is for basic use which can not be traded. Nothing but the rural drinking water for economic use could enter water market. However, the profit-driven character of market is likely to induce the water resources owners to wrong behavior that transferring water for basic use or ecological and environmental use to get more benefits, which is seriously harmful to human's normal lives, ecological environment and social development.

3) Intermediary Agency

The trading of rural drinking water is a part of water rights trade so the intermediary agency is also Water Rights Trading Centre. Water Rights Trading Centre is the place for water rights to trade openly, centrally and regularly, establishing in accordance with the law, with fixed location and close-knit organization. And it is very vital to water rights trading regularly, efficiently and orderly. Water Trading Centre is invested by the government and it's a non-profit institution and comprehensive service agency. The centre relies on transaction commissions to maintain daily operation and offers a variety of service methods and trading means, such as collecting, processing and publishing trading information, arranging the negotiation between both sides, providing legal consulting service and financial service, organizing bidding and auction, etc.

\subsection{Trading Procedure}

The trading procedure is the whole process of rural drinking water trading that from the initial preparation to the final delivery. We should first develop a standardized trading procedure to regulate the trade. The trading procedure of rural drinking water is as follows:

1) Application. The subject of rural drinking water or his broker applies to Water Rights Trading Centre for the trade, fills in application forms containing water quantity, transaction intention and other related contents with required format, and submits the relevant materials. The assignor of rural drinking water should provide proofs of the subject qualification and the ownership of water, while the assignee should offer proofs of the subject qualification, the credit certificates as well as the use of water.

2) Information Release. The centre will release the relevant information after examination and verification. There are four main methods to publish the information: announcements, advertisement, trade fairs and internet. The trading centre would release trading information, such as the place, quantity, term, range of price, contact way, etc., by announcements on the trading floor, which is simple, convenient, cheap but narrow spread. Trading information can be widely spread by advertising on television, radio, newspapers, magazines and other mass media, while this method is expensive. The trading fair of rural drinking water is a good platform to introduce a large number of trading information and to facilitate transactions. It should be well organized and involves large amount of money. It's efficient to put trading information on the internet because it's convenient, informative, wide spread and low cost.

3) Brokered Transaction. The centre actively assists the trades to find counterparties to broker the transactions by trading modes of negotiation, auction or registration.

4) Examination and Approval. Both parties of the transaction apply to the water administrative department for the approval of the transaction and submit relevant materials. The department will examine the transaction within a reasonable period of time. 
5) Contract-signing. Both parties can sign a standard contract of rural drinking water trading in the trading center after receiving the formal approval of the water administrative department.

6) Delivery. Both parties make the payment and delivery in the trading centre, sign the transfer list and pay the transaction commission.

7) Registration. Both parties of the transaction should transfer the ownership of rural drinking water with the contract in the water administrative department within the prescribed period. The department will announce the transfer.

\subsection{Trading Modes}

There are mainly three trading modes of rural drinking water: negotiation, auction and bidding. The buyer and the seller could choose the most suitable mode according to their situation when trading.

1) Negotiation mode. It is that both sides of the transaction reach the agreement on trading conditions as well as the rights and obligations of both sides though negotiation. Negotiation mode have many advantages, such as trading flexibly, operating easily and with low costs. However, this mode limits the range of participants, undermines the competitiveness, and leads information asymmetry. Consequently, the final trading price may deviate from the real value.

2) Auction mode. It is that the highest bidder will access to the rural drinking water in a public auction. Auction is with the principles of openness and fairness that conduce to eliminate information asymmetry, increase the transparency of information, provide equal opportunity to compete, and improve the efficiency of trade. Otherwise, it needs a more complex operation.

3) Bidding mode. It is to trade through a competitive procedure of bidding within the prescribed period that the qualified buyers bid for the water and the seller selects the best buyer to trade with. This mode also has the advantages of auction mode, such as higher degree of transparency of information and equal opportunity to compete. While the disadvantages of bidding mode are larger workload, higher trade costs are longer.

The establishment of rural drinking water market can be shown in Figure 1.

\section{The Operating Mechanism of Chinese Rural Drinking Water Market}

The operating mechanism of Chinese rural drinking water market consists of supply and demand mechanism, price mechanism, competition mechanism and support mechanism, which interact with each other.

First of all, the water prices are determined by the relationship of supply and demand, and the competition between the subjects of the market is also affected by this

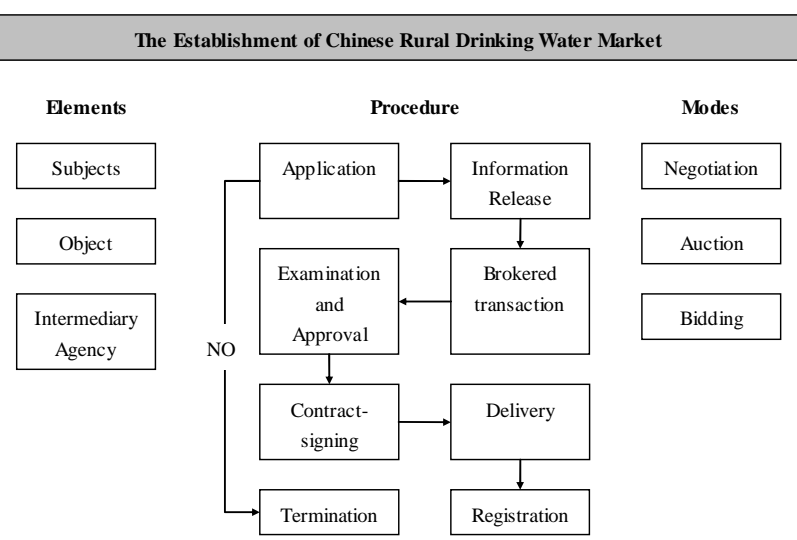

Figure 1. The establishment of Chinese rural drinking water market.

relationship. Furthermore, the equilibrium price is brought in the process of competition, which influences the supply and demand mechanism. Last but not least, the support mechanism offers a favorable trading environment and regulars the market, ensuring the efficiency of the other three mechanisms. The equilibrium of the Chinese rural drinking water market is reached among the interaction between these mechanisms, optimizing the allocation of water resources.

\subsection{Supply and Demand Mechanism}

In the water market, the supply and demand of water resources decide water prices and the behaviors of water consumption. The subjects of rural drinking water market represent the supply and demand. The supply and demand of water is changing. The supply is influenced by the quantity of water available, production scale, the structure of water consumption, water-saving input and other factors. And the demand is related to production scale, changes in water users and consuming behavior, natural precipitation as well as political, cultural and other social factors. Since the transfer of water resources is constrained by regional conditions, the water supply and demand is spatial and temporal disequilibrium.

In the rural drinking water market, the users are likely to pay more to get enough amount of water for the development of living and production when the demand is greater than the supply. However, the users whose marginal output of water resources is less than the marginal cost cannot afford the high price, so they have to adjust their behavior of water consumption, such as adopting water-saving measures, to increase the marginal product of water. Finally, the efficiency of water using will be improved and the phenomenon of water shortage and waste will be eased to some extent.

\subsection{Price Mechanism}

Prices are significant signals to optimize the allocation of 
resources for their sensitivity to the information in the market. In the rural drinking water market, the price mechanism is feeding back trading information and it's an indispensable part of the operating mechanism. It guides the supplier and demand to make reasonable decisions based on the price level and plays an important role to allocate water resources optimally.

Water prices have vital signaling functions that reflecting the water resources of the supply and demand, the scarcity and the evaluation. In the rural drinking water market, prices will fall when the supply is more than the demand, and vice versa. Water prices also show the scarcity of water resources. As economists put it, scarce resources have value so people would rather give up other utility in exchange for it. If a resource is inexhaustible and people can get it without any cost, this resource is not scarce and do not have value. Water prices tell the evaluation of water resources, for instance, water resources with higher prices indicate greater value while these with lower prices present less value.

Water prices can guide water resources to allocate optimally in two ways. On the one hand, they can adjust the behavior of water consumption. Usually, if the prices rise, the water users will adopt water-saving equipment or turn to use water products of lower consumption, reducing water consumption scale. On the other hand, water prices could guide governmental regulation. When water prices increase, which means that the supply is less than the demand, the government can encourage the users to adopt water-saving equipment by some preferential policies, such as reducing some related taxes and fees, increasing the supply to decrease the prices, so that the supply and demand can reach new equilibrium. When the prices are falling rapidly, the government could increase the taxes and fees and buy water resources in the market to recover the prices.

\subsection{Competition Mechanism}

The imbalance between the supply and demand in the market will inevitably result in competition which will drive the supply and demand to reach new equilibrium. The main competition in the rural drinking water market is the competition between the suppliers, the competition between the demanders and the competition between the suppliers and demanders. Since there are no big differences in the quality and service of rural drinking water, prices have become the key factor of competitiveness. For the suppliers, they have to make their water-saving cost below the market average one to hold strong competitive edges. While for the buyers, these with higher marginal output of water resources have the stronger competitiveness. The competition between the buyers leads to the rise in water prices, and then they have to adjust their behavior to maximize the efficiency of water resources, improving the marginal output. Thus, the competition could encourage water-saving behavior and increase the water-using efficiency. In the water market, the competition between the sellers and buyers goes according to the law of value. The sellers prefer higher prices to raise their profits and the buyers like lower prices to reduce the costs, which will reflect the true value of water resources. Generally speaking, fierce competition will make the allocation of water more rational and effective, which is on the premise that the competition is on a fair platform and there are laws and regulations constraining both parties of the contract to ensure the principle of fair competition in market trading.

\subsection{Support Mechanism}

\section{1) Legal Support}

Laws and regulations of the market should be developed. The laws and regulations are the significant support for the market establishing and operating effectively, controlling the various interests of trading subjects and ensuring the market of rural drinking water to develop healthily and sustainably. The legal system of rural drinking water market includes the legal basis and the market trading system. There are legal gaps on the subjects of rural drinking water, the distribution of it, the rights and obligations of its users, the trading system, etc. The development of the trading system would make the trading process more standardized and controlled. It would reduce the trading disputes and costs. The trading system should be made according to the specific circumstances of each region. The laws and regulations of rural drinking water market will be improved in practice and become the strong support for the market running.

2) System Support

The water management system should be improved. On the one hand, we should strengthen watershed management of water resources and establish the comprehensive management institutions of watershed management. Watershed management is the world trend of water resources administration, so China should establish authoritative institutions, without the intervention of local government, to enhance watershed management and ensure the normal operation of rural drinking water market. The institutions should introduce a parallel two-tier system of watershed management committee and the executive agency and the means of market economy as well as the administrative means to optimize the resources allocation. On the other hand, we should implement the integrated management of water affairs both in urban and rural areas. Water authority of local government is the organizational form of integrated management, with the functions of water supply, distribution, drainage, sewage treatment and recycling, and is responsible for the development and utilization of water resources and the 
The Operating Mechanism of Chinese Rural Drinking Water Market

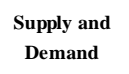

Mechanism

\begin{tabular}{|c|c|c|}
\hline & Quantity & \\
\hline $\begin{array}{l}\text { Water } \\
\text { Supply }\end{array}$ & Structure & $\begin{array}{l}\text { Water } \\
\text { Demand }\end{array}$ \\
\hline
\end{tabular}

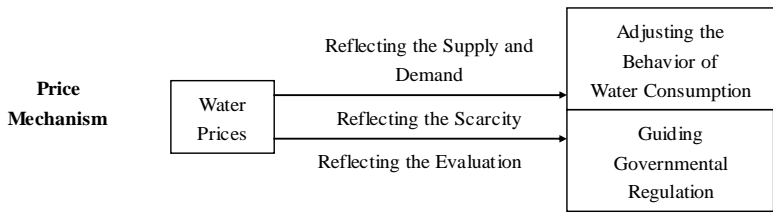

Competition Mechanism

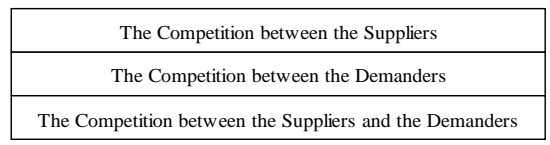

Support Mechanism

\begin{tabular}{|c|c|c|}
\hline Legal & System & Organization \\
Support & Support & Support \\
\hline
\end{tabular}

Figure 2. The operating mechanism of Chinese rural drinking water market.

construction and management of flood control and drainage facilities.

3) Organization Support

The water users association should be created. The water users association is a social organization composed of voluntary water users, democratically elected to manage water consumption. It is one of the successful modes in the world for its many advantages. First, it can increase the efficiency of water resources management. The association is the bridge between the government and water users, involved in the formulation of relevant policies and regulations, which improves the information transparency of the process and protects the group's interests. In addition, as the members are familiar with each other, the one who breaches the rules will lose his credibility and be deprived of the opportunities of longterm cooperation and the lasting interests. This reputation mechanism and the dynamic game will encourage water users to supervise and regulate each other's behavior. Second, the association can reduce the costs of water trading. The cost of information searching is very low because the members are interconnected. The familiarity between the members decreases the cost of bargaining. The association can also reduce the cost of the supervision of contract-breaching due to its arbitration role to resolve disputes. Third, the association conduces to the improvement of water supply and management. Individual water users are always in a weak position in the face of water companies but the association has equal status in negotiations to ensure the transfer and communication of the information and enhance the symmetry of information. Therefore, the water users association is an organi- zation support for the operating of rural drinking water market.

The operating mechanism of the market is illustrated in Figure 2.

\section{Conclusion}

Consequently, in order to establish Chinese rural drinking water market, we should clearly define the subjects, objects and intermediary agency of market trading and develop a normal trading procedure. Therefore, we can standardize the whole process of rural drinking water trading that from the initial preparation to the final delivery. And then we should adopt a suitable trading mode. The operating of Chinese rural drinking water market is affected by the supply and demand mechanism, the price mechanism and the competition mechanism, as well as support mechanism including laws and rules, management system and organization factor. Finally, we are able to establish and develop Chinese rural drinking water market, optimizing the allocation of water resources.

\section{REFERENCES}

[1] B. Parsons, "Clean Living, First Nations and Water," Canadian Consulting Engineer, Vol. 10, No. 4, 2003, pp. 21-24.

[2] H. G. Peterson, "Rural Drinking Water and Waterborne Illness,” 2006. http://www.safewater.org

[3] S. Jones, "Participation as Citizenship or Payment: A Case Study of Rural Drinking Water Governance in Mali,” Water Alternatives, Vol. 4, No. 1, 2011, pp. 54-71.

[4] A. G. Jie and M. J. Gong, "Research on the Operating Mechanism of Rural Drinking Water Project Management," China Water Power, Vol. 11, No. 11, 2003, pp. 32-33.

[5] C. X. Ma, "Thoughts on the Relationships of Rural Water Project Implementation,” Shandong Water Resource, Vol. 7, No. 2, 2005, pp. 3-5.

[6] F. H. Gao, "Research on the Project Construction of Safe Rural Drinking Water and the Optimization of the Allocation of Water Resources in Binzhou," Shandong University, Jinan City, 2007.

[7] H. S. Zhang and Y. Liu, "The Situation, Problems and Solutions of the Project Management of Safe Rural Drinking Water," China Water Power, Vol. 17, No. 10, 2007, pp. 30-32.

[8] Y. Q. Yang, Q. J. Pang and Y. Song, "Research on the Problems of Chinese Rural Drinking Water Safety,” Journal of Shandong Agricultural University (Science Edition), Vol. 39, No. 1, 2008, pp. 119-122.

[9] M. Hu, L. Jiang and H. He, "Research on the Setting Standard of Automatic Control System of Safe Rural Drinking Water Project," Water and Wastewater Engineering, Vol. 36, No. 2, 2010, pp. 113-116.

[10] Y. Q. Li, "Research on the Management Mode of Safe 
Rural Drinking Water Project in Zhangqiu,” Shandong University, Jinan City, 2010.

[11] H. J. Vaux and E. Howittr, "Managing Water Scarcity: An Evaluation of Interregional Transfers," Water Resources Research, Vol. 20, No. 7, 1984, pp. 785-792. doi:10.1029/WR020i007p00785

[12] M. W. Rosengrant and H. P. Binswager, "Markets in Tradable Water Rights: Potential for Efficiency Gains in Developing Country Water Resource Allocation,” World Development, Vol. 22, No. 11, 1995, pp. 1613-1625. doi:10.1016/0305-750X(94)00075-1

[13] T. Mateen, "Property Rights to Water: How to Improve Use and Resolve Water Conflicts," Public Policy for the Private Sector, Vol. 34, No. 4, 1995, pp. 3-6.

[14] A. Manuel, A. G. Jos and N. M. Mez-Lim, "Local Water Markets for Irrigation in South Spain: A Multi-Criteria Approach,” The Australian Journal of Agricultural and Resource Economics, Vol. 46, No. 1, 2002, pp. 21-43. doi:10.1111/1467-8489.00165

[15] C. W. Howe and G. Christopher, "Water Transfers and Their Impacts: Lessons from Three Colorado Water Markets,” Journal of the American Water Resources Association, Vol. 39, No. 5, 2003, pp. 1055-1065. doi:10.1111/j.1752-1688.2003.tb03692.x

[16] E. Hadjigeorgalis, "A Place for Water Markets: Performance and Challenges,” Review of Agricultural Economics,
Vol. 31, No. 1, 2008, pp. 50-67. doi:10.1111/j.1467-9353.2008.01425.x

[17] H. Huang, "Characteristics and Development Measures of Water Market,” China Water Power, Vol. 12, No. 6, 2000, pp. 26-28.

[18] A. H. Jiao, "Research on the Operating Mode of Chinese Water Market," Advances in Science and Technology of Water Resources, Vol. 8, No. 5, 2001, pp. 24-25.

[19] A. G. Hu, "Public Policy Quasi-Market and Political and Democratic Consultation of Water Resources Allocation in Transition Period," Review of Economic Research, Vol. 20, No. 1, 2002, pp. 18-21.

[20] Y. Y. Li, "Water Market and Water Rights Trading," Planning and Design of Water Resources, Vol. 2, No. 12, 2004, pp. 9-12.

[21] Y. X. Ge, "Research on the Operating Mechanism of Water Rights Market,” Shandong Social Sciences, Vol. 10, No. 2, 2006, pp. 88-90.

[22] X. Q. Ma and J. M. Han, "Research on the System Innovation of Chinese Water Rights," Economic Review, Vol. 11, No. 9, 2008, pp. 28-30.

[23] H. J. Jiang and H. L. Pan, "Research on the Theory of Administrative Monopoly in Chinese Water Rights Market,” Journal of Hohai University (Philosophy and Social Science Edition), Vol. 12, No. 3, 2010, pp. 53-56. 